\title{
Article
}

\section{Impact Strength of Hybrid Epoxy-Basalt Composites Modified with Mineral and Natural Fillers}

\author{
Danuta Matykiewicz $^{1, * \mathbb{D}}$, Mateusz Barczewski ${ }^{1} \mathbb{D}$, Marwan Suleiman Mousa ${ }^{2} \mathbb{D}$, Mavinkere Rangappa Sanjay ${ }^{3} \mathbb{D}$ \\ and Suchart Siengchin ${ }^{3}(\mathbb{D}$ \\ 1 Institute of Materials Technology, Faculty of Mechanical Engineering, Poznan University of Technology, \\ Piotrowo 3, 61-138 Poznań, Poland; mateusz.barczewski@put.poznan.pl \\ 2 Department of Physics, Mu'tah University, Al-Karak 61710, Jordan; mmousa@mutah.edu.jo \\ 3 Natural Composites Research Group Lab, Department of Materials and Production Engineering, \\ The Sirindhorn International Thai-German Graduate School of Engineering (TGGS), King Mongkut's \\ University of Technology North Bangkok (KMUTNB), Bangkok 10800, Thailand; \\ mcemrs@gmail.com (M.R.S.); suchart.s.pe@tggs-bangkok.org (S.S.) \\ * Correspondence: danuta.matykiewicz@put.poznan.pl; Tel.: +48-616-475-858
}

check for updates

Citation: Matykiewicz, D.; Barczewski, M.; Mousa, M.S.; Sanjay, M.R.; Siengchin, S. Impact Strength of Hybrid Epoxy-Basalt Composites Modified with Mineral and Natural Fillers. ChemEngineering 2021, 5, 56. https://doi.org/ 10.3390/chemengineering5030056

Academic Editors: Alírio

E. Rodrigues and Andrew S. Paluch

Received: 23 June 2021

Accepted: 24 August 2021

Published: 31 August 2021

Publisher's Note: MDPI stays neutral with regard to jurisdictional claims in published maps and institutional affiliations.

Copyright: (c) 2021 by the authors. Licensee MDPI, Basel, Switzerland. This article is an open access article distributed under the terms and conditions of the Creative Commons Attribution (CC BY) license (https:/ / creativecommons.org/licenses/by/ $4.0 /)$.

\begin{abstract}
The aim of this study was to evaluate the influence of mineral and natural additives $(2.5 ; 5 ; 10 \mathrm{wt} . \%)$ on the impact strength of epoxy-basalt composites. Three types of filler were used to modify the epoxy matrix: basalt powder (BP), basalt microfiber (BF) and sunflower husk ash (SA). The impact strength and the maximum force were determined for the materials. The results of the conducted research confirm that the addition of a powder fillers to the epoxy matrix of basalt fiber reinforced composites is an effective method of improving their impact characteristic. The introduction of fillers to epoxy resin allowed to improve the impact properties of all tested groups of laminates. Moreover, in all cases, the introduction of the filler increased the maximum force needed to damage the composite sample and their hardness. For the modified materials, an increase in impact strength was recorded, respectively: by $44 \%$ for composites with BP, by $7.5 \%$ for composites with $\mathrm{BF}$ and by $2.5 \%$ for composites with SA.
\end{abstract}

Keywords: epoxy composites; basalt fiber; basalt powder; sunflower husk ash; impact strength

\section{Introduction}

Metal, ceramics and plastic are commonly used construction materials depending on particular needs. Composites reinforced with fibers have become very common in recent years, and have broadly replaced popular metal and polymer materials in many industries [1,2]. They are used as construction elements in planes, cars, boats and as finishing ingredients in building. The growth of ecological activities is translating into a progress in their application in the production of natural fibers made of plants such as flax, hemp, as well as mineral fibers characterized by reduced ecological impact, including basalt. Polymer composite materials due to their complex structure and many functions constitute an attractive research topic for many groups of scientists [3,4]. Depending on the type of fiber used, such as natural fiber, mineral fiber and synthetic fiber, these composites are characterized by high mechanical strength and favorable thermal properties. The use of the potential of reinforcing fibers strictly depends on the choice of polymer and the proper arrangement of all components in the layered material [5].

Epoxy resin in liquid form, pastes or powder after curing is characterized by high resistance to atmospheric and chemical factors, strength and hardness [6]. However, due to the brittleness, the epoxy material is reinforced with fibers or subjected to chemical or physical modification by introducing various types of powder fillers such as: carbon nanotubes, graphene, fullerenes, silica, or natural waste filler. Hybrid polymer composites contain fillers and/or modifiers of a different structure, shape and functionality, thanks 
to which they display unique useful, technological and processing properties [7]. Basalt fiber $(\mathrm{BF})$ obtained from volcanic rock is characterized by good mechanical strength, thermal and chemical stability and indicated good compatibility with many polymer matrix [8,9]. Interfacial bonding strength of the epoxy materials with basalt fiber during micromechanical and thermomechanical analyses was studied by Mun et al. [10].

Prasath et al. reported that the alternating arrangement of basalt and flax fibers in the composite showed better performance in low velocity impact and compression after impact tests [11]. On the other hand, Fiore at al. described that replacing the outer layers of jute with basalt layers in laminates increases the durability of structures exposed to aging in salt spray conditions [12].

Russo et al. examined impact damage performance of basalt fiber composites manufactured from different matrices such as a polyamide 6, a vinyl ester resin and an epoxy resin [13]. Polyamide-based materials indicated high rigidity in comparison to the vinyl and epoxy composites. Dorigato et al. proved superior fatigue properties of epoxy composites reinforced with basalt in comparison to glass-epoxy composites [14]. The influence of graphene oxide adding on the mechanical performance of $\mathrm{BF} /$ epoxy composites was described by Jamali [15]. Arshad et al. proved that the introduction of coir fiber and TiC nanoparticles into basalt/epoxy composites showed a significant enhancement in their mechanical and thermal properties [16]. Toorchi et al. described that addition of the nanozirconia/graphene oxide into basalt fiber-epoxy materials increase flexural strength and wear resistance [17]. The incorporation of micro nano basalt fiber (MNBF) into the epoxy matrix leads to improved properties such as strength, chemical resistance and fire resistance, as described by Rassokhin et al. [18]. Ricciardi et al. showed that SF6 plasma treatment increased the hydrophobicity and impact resistance of basalt-epoxy composites [19]. Demirci et al. found that the addition of $\mathrm{SiO}_{2}$ nanoparticles to BFR/epoxy composites improved tensile strength, maximum force, and rebound energy. Moreover, the incorporation of $\mathrm{SiO}_{2}+$ MWCNT nanohybrid into BFR/epoxy materials increased the impact resistance and tensile strength more than adding pure MWCNT [20]. The beneficial aspects of using basalt powder as fillers for epoxy composites were presented in our previous work [21,22]. The valuable use of rice husk ash in polymer composites was presented in the work in [23]. The beneficial impact of bio-based magnesium phytate and rice husk ash on epoxy resin flame retardancy was proved by Xu et al. [24]. However, the use of sunflower husk ash in combination with epoxy resin has not yet been reported.

In order to improve the stiffness and mechanical characteristics of the epoxy matrix, it is reinforced with fibers, while in order to obtain specific functionalities such as high thermal resistance, hardness, impact strength, wear resistance, epoxy resins are combined with natural, mineral or synthetic powder fillers [25]. Therefore, the aim of this study was to compare the effect of mineral and natural fillers on the impact strength and hardness of epoxy composites reinforced with basalt fiber. The novelty aspect of the research is the fact that materials of natural origin with different functionalities, such as basalt powder, basalt microfiber and sunflower husk ash, were used as epoxy matrix modifiers. In addition, it has been proven that waste materials can be successfully used as full-value modifiers of polymer compositions.

\section{Materials and Methods}

\subsection{Materials}

In this study, three types of epoxy/basalt fabric composites were produced: composites with basalt powder (BP), composites with basalt microfiber (BF) and composites with sunflower ash (SA). The following epoxy matrices were chosen for preparation of the specific material types: for BP composites-the epoxy resin Epidian 6 based on bisphenol A and curing agent-triethylenetetramine, (CIECH Sarzyna S.A., Poland); for BF composites-the epoxy resin Epodur CHS 574-0492 and curing agent CHSE 574-0492 (SPOLCHEMIE, Czech Republic); for SA composites-the epoxy resin (with 37\% biobased content) SuperSap ONE and curing agent hardener SuperSap ONS (Entropy resin). 
The basalt powder (BP) composition (BP) (Mine PGP BAZALT, Wilkowo, Złotoryia, Poland) is presented in Table 1. A detailed analysis of the basalt powder particle size distribution is presented in our previous work [21]. On average, the size of the basalt particles was $10 \mu \mathrm{m}$.

Table 1. The chemical composition of basalt powder and microfiber.

\begin{tabular}{ccc}
\hline$[\%]$ & Basalt Powder & Basalt Microfiber \\
\hline $\mathrm{SiO}_{2}$ & 49.5 & $41-55$ \\
$\mathrm{Al}_{2} \mathrm{O}_{3}$ & 15 & $10-20$ \\
$\mathrm{CaO}$ & 9.6 & $6-13$ \\
$\mathrm{FeO}$ & 8.7 & $7-18$ \\
$\mathrm{Fe}_{2} \mathrm{O}_{3}$ & 3.7 & $1-15$ \\
$\mathrm{MgO}$ & 6.8 & $2-7.5$ \\
$\mathrm{Na}_{2} \mathrm{O}$ & 2.9 & $0.5-3$ \\
$\mathrm{TiO}_{2}$ & - & - \\
$\mathrm{K}_{2} \mathrm{O}$ & 1.2 & - \\
$\mathrm{P}_{2} \mathrm{O}_{5}$ & 0.4 & - \\
$\mathrm{MnO}$ & 0.2 & - \\
$\mathrm{Mn}$ & 0.15 & - \\
$\mathrm{Zn}$ & 0.0105 & - \\
$\mathrm{Cu}$ & 0.0087 & - \\
$\mathrm{Co}$ & 0.0048 & - \\
$\mathrm{B}$ & 0.005 & - \\
$\mathrm{Mo}$ & 0.00015 &
\end{tabular}

Unsized milled basalt microfiber, MICF0021 (BF) (Incotelogy, Germany), was used to modify the epoxy matrix of BF series composites. The fibers had a diameter of 8-13 $\mu \mathrm{m}$, a length of 5-150 $\mu \mathrm{m}$, and a density of $2.65-2.75 \mathrm{~g} / \mathrm{cm}^{3}$. The chemical composition of basalt microfibers according to the data provided by the manufacturer is presented in Table 1.

According to Paleckienè et al. [26] sunflower husk ash contain the primary and secondary plant nutrients-phosphorus $\left(10.94 \% \mathrm{P}_{2} \mathrm{O}_{5}\right)$, potassium $\left(25.84 \% \mathrm{~K}_{2} \mathrm{O}\right)$, calcium $(19.07 \% \mathrm{CaO})$, magnesium $(18.58 \% \mathrm{MgO})$, and micronutrients such as zinc, copper, cobalt, manganese, iron, and molybdenum. Sunflower husk ash was obtain in the pyrolysis process at $650{ }^{\circ} \mathrm{C}$ and next the fraction $\sim 50 \mu \mathrm{m}$ was separated using a sieve analyzer and application as a filler for epoxy resin. Particle size distribution of the sunflower husk ash was assessed using laser particle sizer Fritsch ANALYSETTE 22 apparatus in a range of 0.08-2000 mm. Particle size distribution function (Q3(x)) and its derivative (dQ3(x)) as a function of particle size (x) were demonstrated in Figure 1.

Basalt fiber woven fabric (BASALTEX) type BAS 210.1270.P with $210 \mathrm{~g} / \mathrm{m}^{2}$ was applied as reinforcement.

\subsection{Sample Preparation}

The epoxy matrix was blended using a mechanical agitator Disperlux (proLAB, Gda'ńsk, Poland), with 2.5, 5 and 10 wt.\% of filler to the total weight of mixture, respectively, under sub atmospheric pressure conditions. The mixtures were then combined with an appropriate amount of hardener. All types of composites were made of six layers of basalt woven fabric and were manufactured in the form of the hand lay-up method. The composites were made in the form of plates with dimensions of $300 \mathrm{~mm} \times 300 \mathrm{~mm}$, then the samples for impact tests were cut using the water cutting technology. 


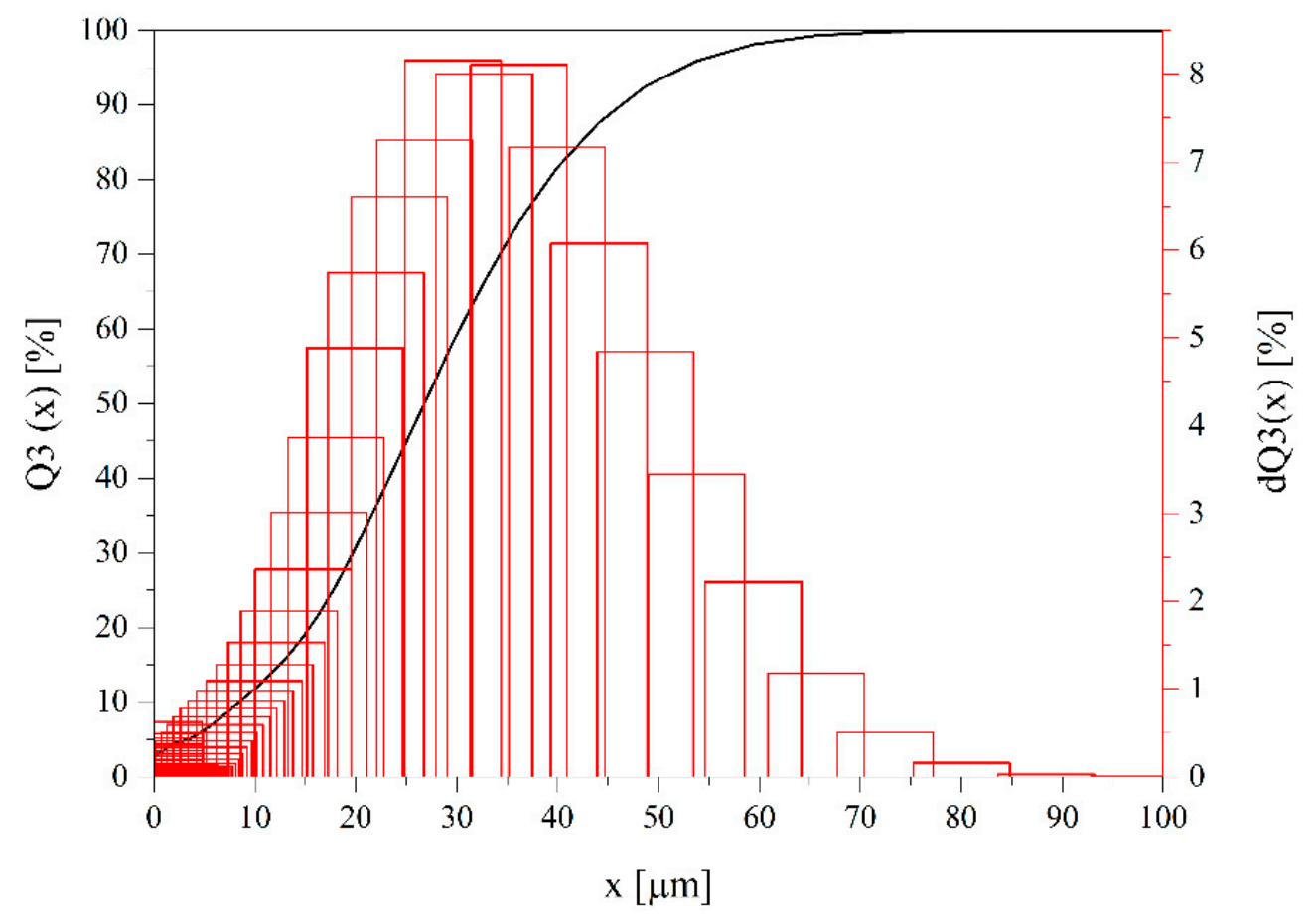

Figure 1. Particle size distribution of sunflower husk ash.

\subsection{Methods}

The structure of fillers was assessed with a scanning electron microscope (SEM) Carl Zeiss Evo 40 (Oberkochen, Germany) and with an electron accelerating voltage of $12 \mathrm{kV}$. All samples were coated with a layer of gold.

The impact strength of the unnotched composites samples was measured by the Charpy method (ISO 179) at room temperature. Moreover, the peak load as the maximum force (Fmax) was measured during the test. A Zwick/Roell HIT 25P impact tester with a $5 \mathrm{~J}$ hammer was utilized.

The hardness of the laminates was examined with an ASTM D2583 standard Barcol hardness tester GYZJ-934-1 (Barber Colman Co., Loves Park, IL, USA).

\section{Results}

\subsection{Structure of the Fillers}

The structure of the used fillers is shown in the Figure 2. Basalt powder possess a fine grain structure with hard diopside and augite phase [27]. Hence, composites filled with basalt powder indicate enhance abrasion and wear resistance. Basalt micro fiber is made from a continuous roving using drum chopping machines and next is ground to reduce its length [28]. Therefore, the photos of BF show rough and sharp edges of the fibers. The sunflower husk ash is very powdery and usually does not agglomerate, the average particle size is up to 20 to $50 \mu \mathrm{m}$. The particle size distribution of sunflower husk ash is shown in Figure 1. 


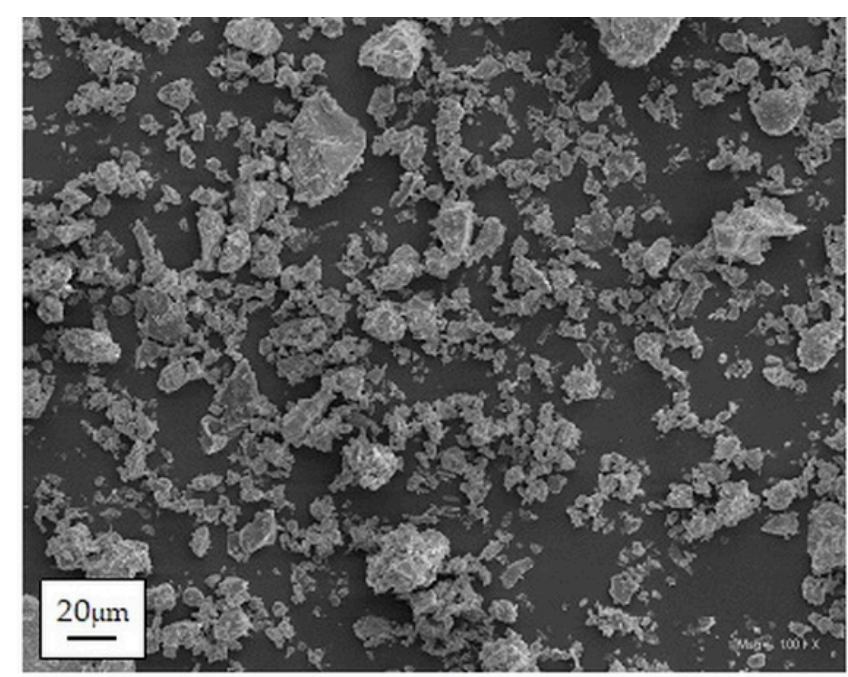

(a)

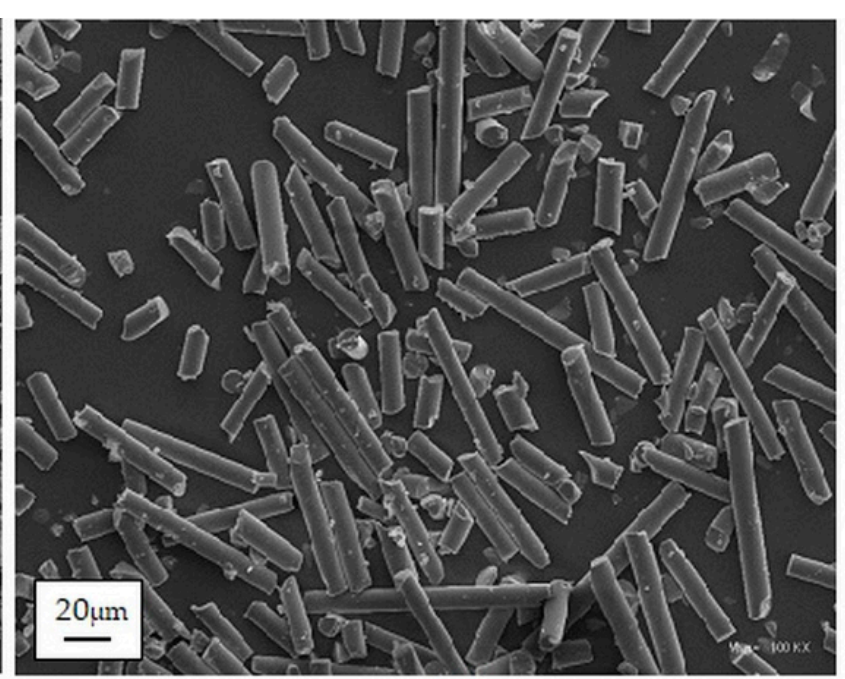

(b)

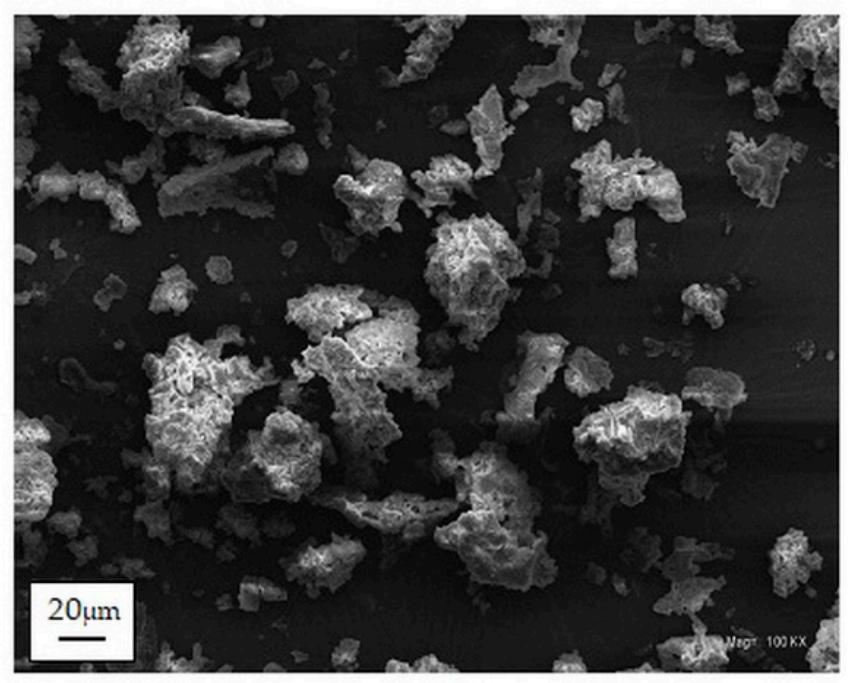

(c)

Figure 2. SEM images of the fillers: (a) basalt powder, (b) basalt micro fiber, (c) sunflower husk ash.

\subsection{Impact Strength}

Layered composites are sensitive to the effects of lateral impact loads that often occur during their exploitation as construction materials. Impact strength is a measure of the brittleness of materials determined by the work required to dynamically break the specimen and related to the size of the specimen cross-section. In laminates, we can distinguish the following types of damage caused by the acting force: matrix cracks along the fibres caused by their stretching, compression or shear; delamination caused by stresses between the individual layers of the laminate and damage to the fibres due to the shear forces that arise when indenting the acting element and on the unloaded side of the laminate on the effect of bending stresses $[29,30]$. Moreover, in order to define the application potential of a composite with a new type of powder filler, a thorough analysis of its impact properties is important. The results of impact strength and the maximum force needed to break the sample are shown in Table 2. In addition, the results obtained for pure epoxy resin without fillers are also included. The impact strength values of the tested samples ranged from 34 to $61\left[\mathrm{~kJ} / \mathrm{m}^{2}\right]$. Due to the different types of epoxy monomers used as a matrix in composites, the $0 \mathrm{BP}, 0 \mathrm{BF}$ and $0 \mathrm{SA}$ samples were characterized by different values of impact strength and maximum force 
Table 2. Impact values of the tested composites and epoxy matrices.

\begin{tabular}{ccc}
\hline Sample & $\begin{array}{c}\text { Impact Strength } \\
{\left[\mathbf{k J} / \mathbf{m}^{\mathbf{2}]}\right.}\end{array}$ & $\begin{array}{c}\text { Maximum Force } \\
{[\mathbf{N}]}\end{array}$ \\
\hline epoxy matrix & $13.5 \pm 2.4$ & $160.2 \pm 2.1$ \\
0 BP & $34.4 \pm 2.9$ & $419.1 \pm 8.1$ \\
$2.5 \mathrm{BP}$ & $46.7 \pm 2.1$ & $517.7 \pm 6.2$ \\
$5 \mathrm{BP}$ & $47.3 \pm 2.0$ & $524.1 \pm 9.3$ \\
10 BP & $49.4 \pm 1.8$ & $497.7 \pm 8.8$ \\
\hline epoxy matrix & $8.2 \pm 1.5$ & $120.1 \pm 1.7$ \\
0 BF & $55.2 \pm 1.9$ & $216.5 \pm 6.1$ \\
2.5 BF & $45.9 \pm 1.7$ & $233.7 \pm 4.2$ \\
5 BF & $49.4 \pm 2.1$ & $230.5 \pm 3.8$ \\
10 BF & $59.3 \pm 1.8$ & $226.4 \pm 5.9$ \\
\hline epoxy matrix & $4.3 \pm 1.8$ & $98.1 \pm 2.5$ \\
0 SA & $59.7 \pm 2.2$ & $188.1 \pm 2.4$ \\
2.5 SA & $61.2 \pm 2.4$ & $230.8 \pm 2.2$ \\
5 SA & $60.2 \pm 1.9$ & $215.6 \pm 2.1$ \\
\hline SA & $60.1 \pm 2.1$ & $201.1 \pm 2.7$ \\
\hline
\end{tabular}

In the group of composites modified with basalt powder, the samples with the highest $\mathrm{BP}$ content were characterized by the highest impact strength. The presence of hard mineral phases in basalt powder has a positive effect on the improvement of the stiffness of the brittle epoxy matrix [21,31]. In addition, the effect of a reinforced interface between the applied basalt fiber and the polymer matrix was obtained for effective tension transfer between the epoxy and the fiber. The greatest $\mathrm{F}_{\max }$ value in this composite group was recorded for the $5 \mathrm{BP}$ sample. It can be assumed that the concentration of $5 \mathrm{wt} . \%$ will be optimal to obtain favorable impact properties of these materials. Moreover, the highest value of force was noted for the composite $5 \mathrm{BP}$, which may confirm its most homogeneous structure without defects that could promote cracks. The Figure 3 shows an enlargement of the sample damage area. The following effects can be observed during the cracking of a layered composite: resin matrix cracking, fiber-matrix debonding, delamination, and fiber pull-out [32]. It can be observed that the reference sample was damaged the most and the 5 BP sample the least (Figure 3). For all composites of the BP series, local delamination and damage of the structure of the layered material was observed. For the $5 \mathrm{BP}$ composite, mainly cracking of the epoxy matrix was observed, which may indicate its good adhesion to the fibers. The typical load-displacement curves for a laminate with BP was presented in Figure 4 . The shape of the force and displacement curve contains important information about the cracking mechanism of layered composites.

The two most common cracking effects can be observed in curves: after a sharp decrease, the load increases again, which relates to the load transfer to the undamaged composite layers and in this case the laminate shows delamination and damage [32]. In the second case, the load after reaching the maximum drops to almost zero and does not increase again, which is a sign of a perforation of the laminate. The shape of the curves in Figure 4 shows that the tested composites first delaminated and then broke, which is confirmed by the picture (Figure 3). 

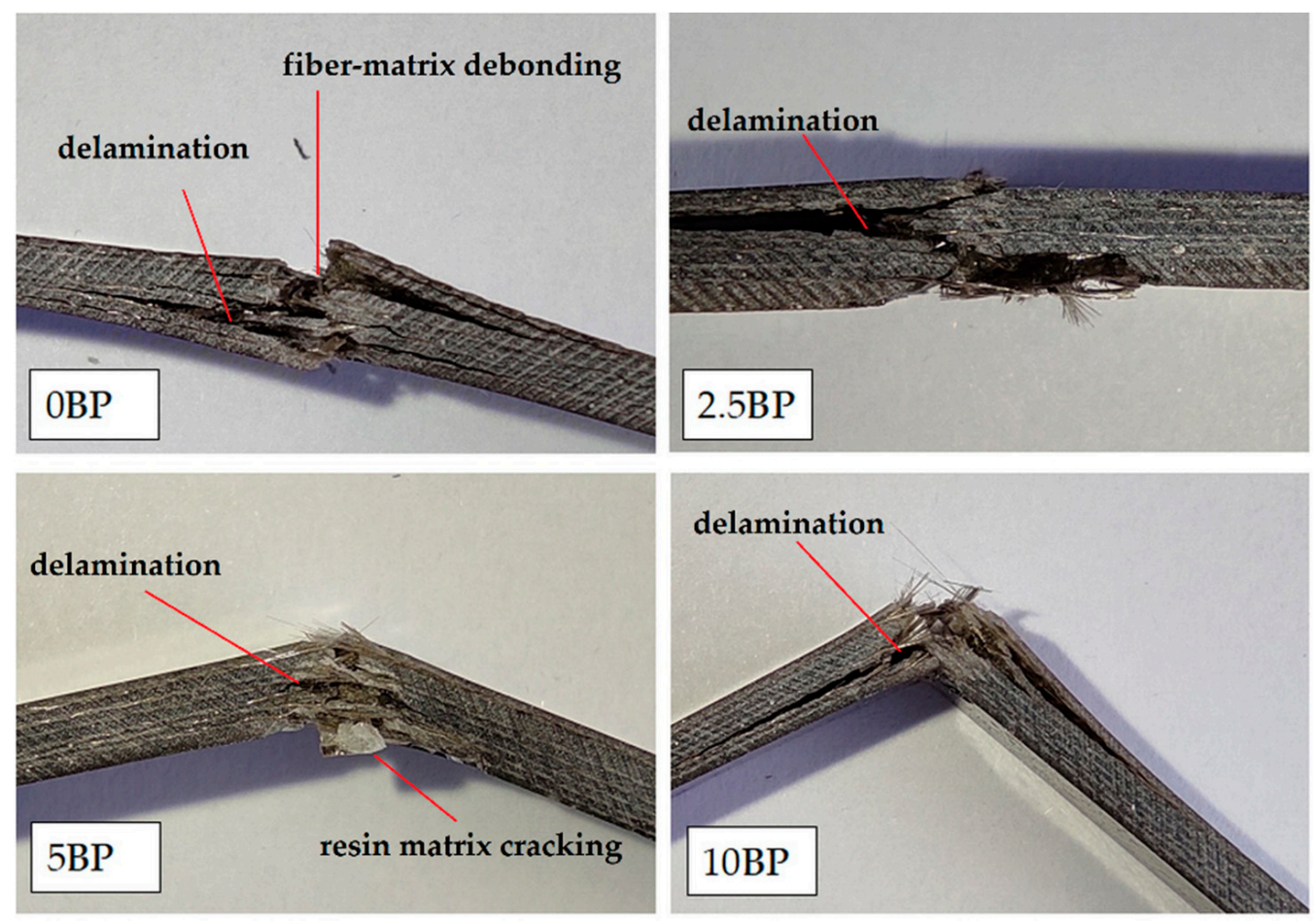

Figure 3. Images of the damaged area of composites modified with basalt powder after the impact test.

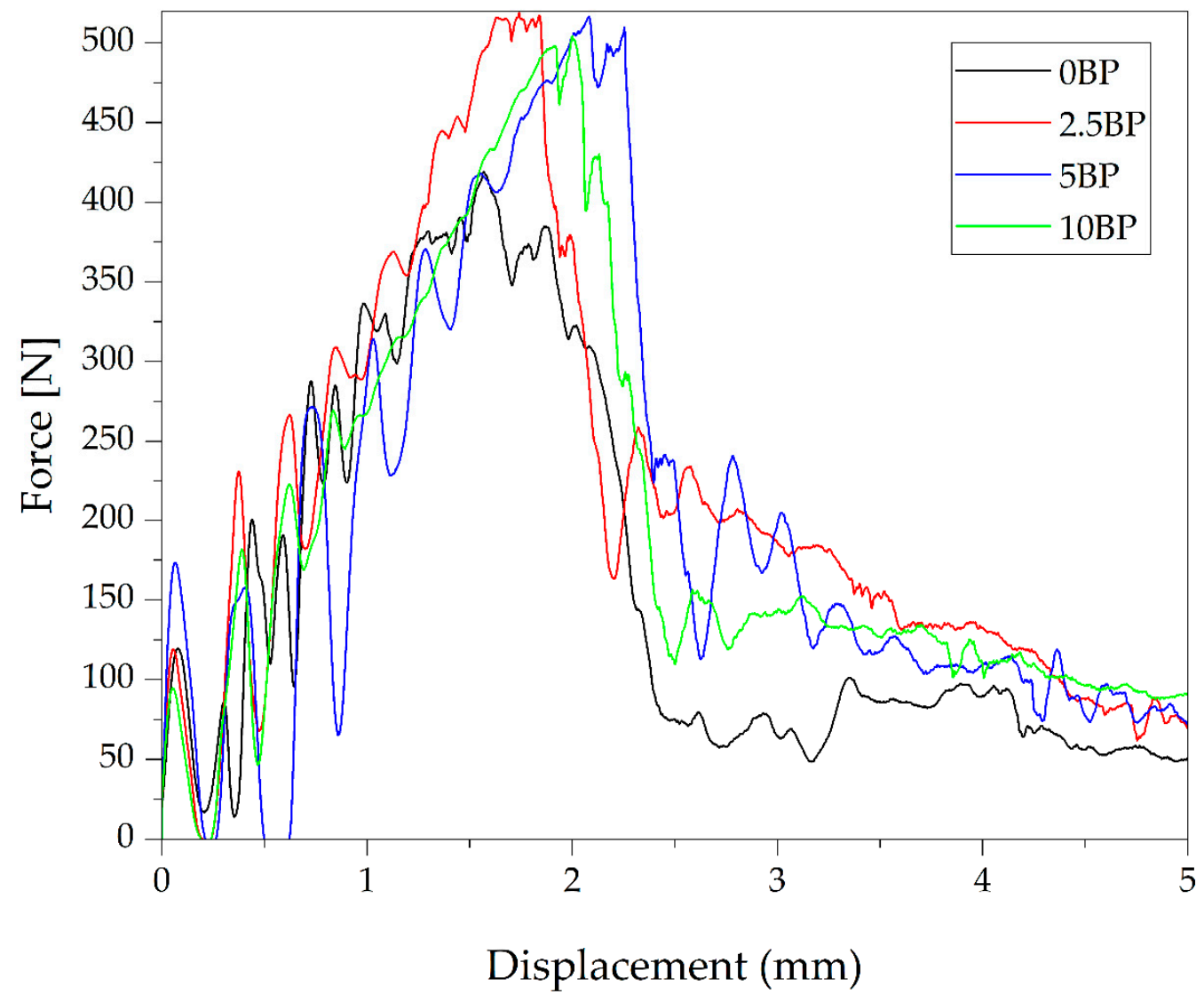

Figure 4. The load-displacement curves of the investigated composites with basalt powder. 
For composites modified with basalt microfiber, the impact values ranged from 45 to $59\left[\mathrm{~kJ} / \mathrm{m}^{2}\right]$. The highest value was recorded for the sample with the highest BF additive content. The image of composites after the impact test and photos of the break point are shown in Figure 5. The presence of rigid basalt microfibers in the epoxy matrix leads to the improvement of its stiffness and reduces its brittleness. In addition, composites containing 10 wt. \% basalt microfibers were characterized by the smallest area of destruction as well as their structure not being completely damaged in comparison to samples $0 \mathrm{BF}$ and $2.5 \mathrm{BF}$ (Figure 5). These results show that modifying the epoxy matrix is an effective method of improving the mechanical behavior of fiber composites [33].
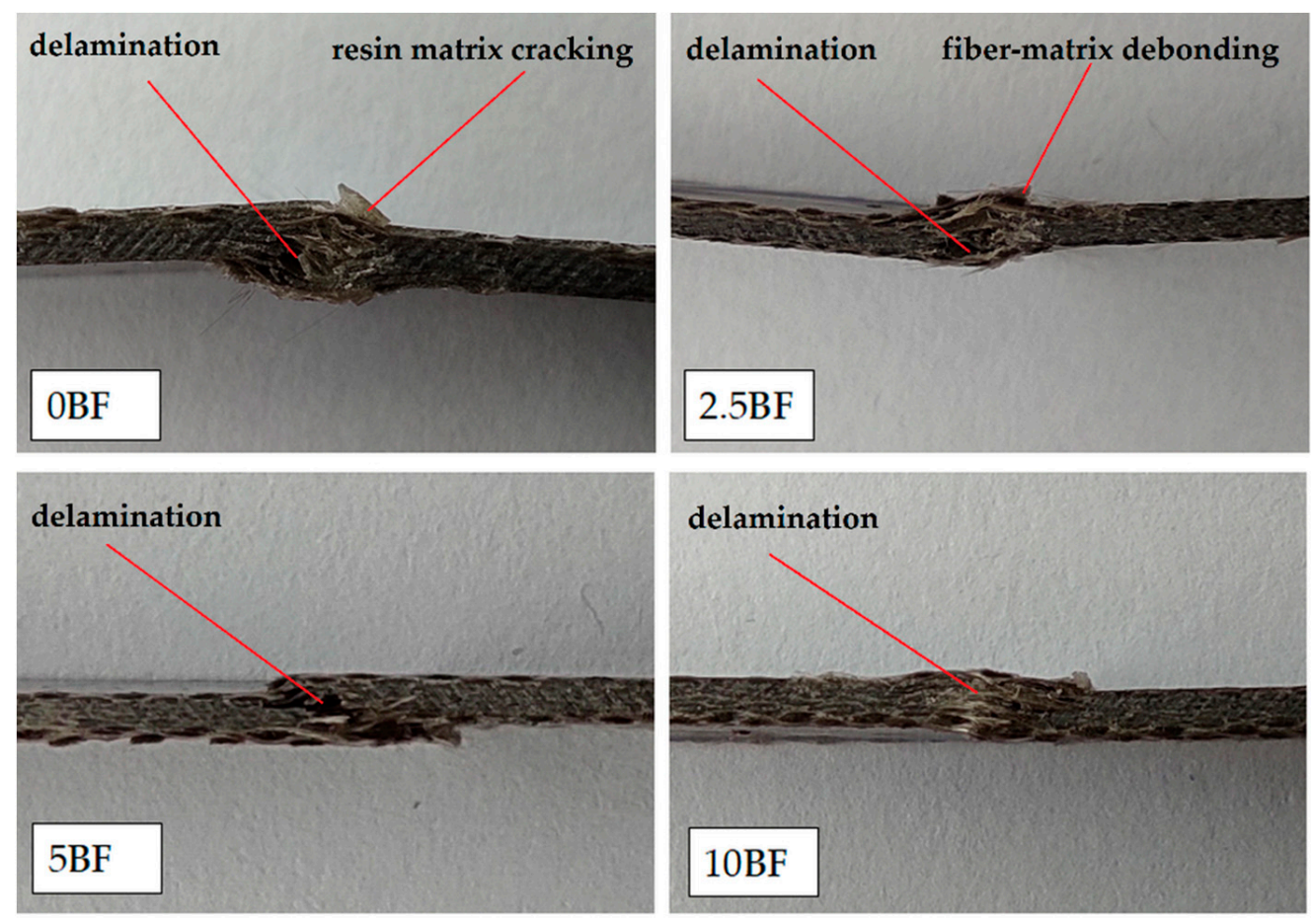

Figure 5. Images of the damaged area of composites modified with basalt micro fiber after the impact test.

Figure 6 shows the force-displacement curves, where it can be observed that after reaching $F_{\max }$, the load drops sharply and then begins to increase. This curve shape confirms the occurrence of delamination of the composites structure as a result of the impact force. All composites containing micro basalt fiber in the epoxy matrix were characterized by a much higher maximum force compared to the unmodified sample.

Among the tested composites modified with filler, the group of composites with sunflower husk ash the most homogeneous properties, i.e., the average impact strength of $60 \mathrm{~kJ} / \mathrm{m}^{2}$. The enhancement effect by incorporating guinea corn husk ash into the epoxy matrix has also been described by Daramola et al. [34]. In turn, the addition of $1 \mathrm{wt}$ \% bagasse ash to hybrid epoxy composites reinforced with sisal/flax and sisal/kenaf fibers significantly improved their impact strength [35]. Furthermore, incorporation of groundnut shell ash into the epoxy/banana fiber composites increases the impact strength of material [36]. Figure 7 shows that the composites were delaminated locally in the impact point. 


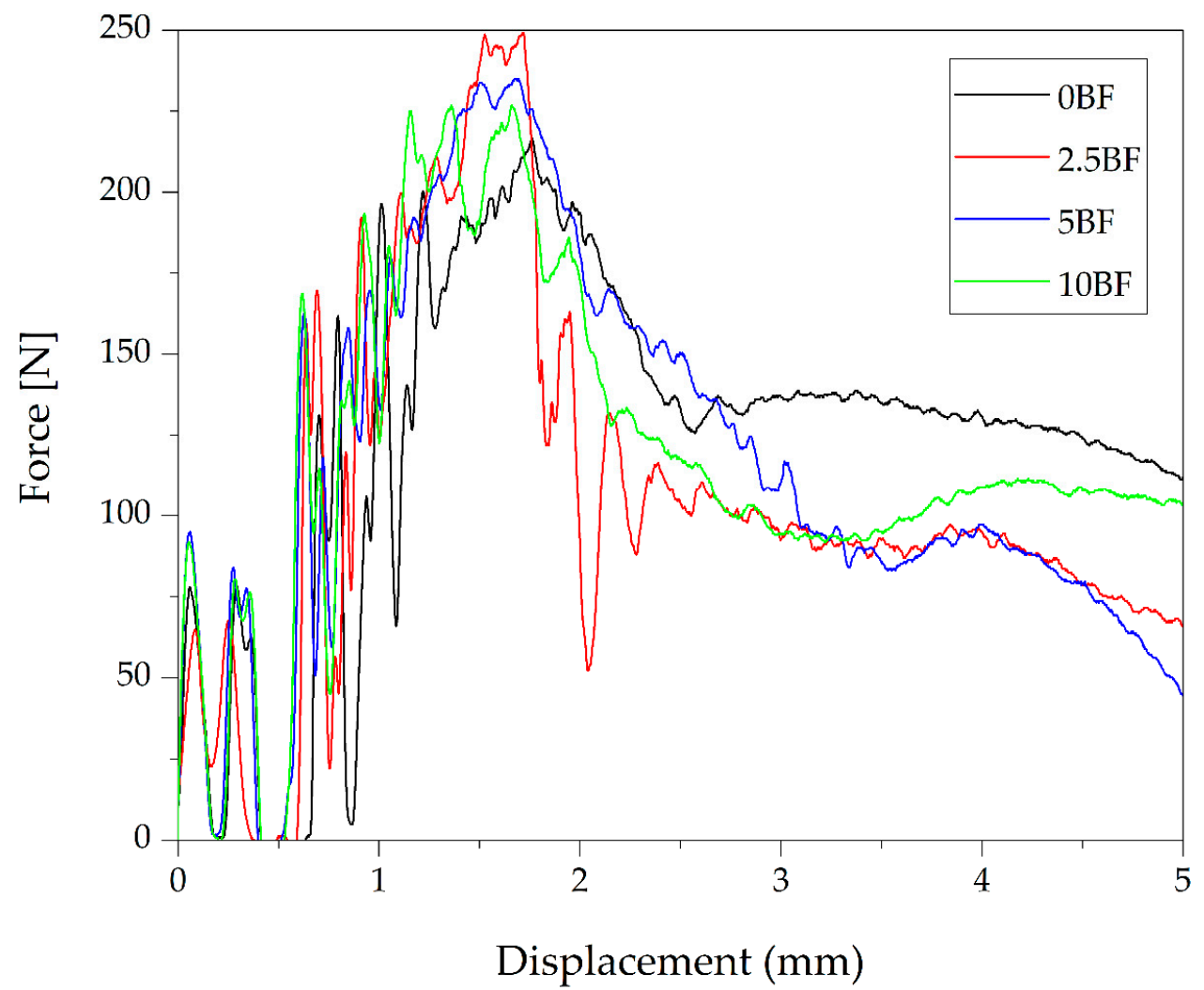

Figure 6. The load-displacement curves of the investigated composites with basalt microfiber.
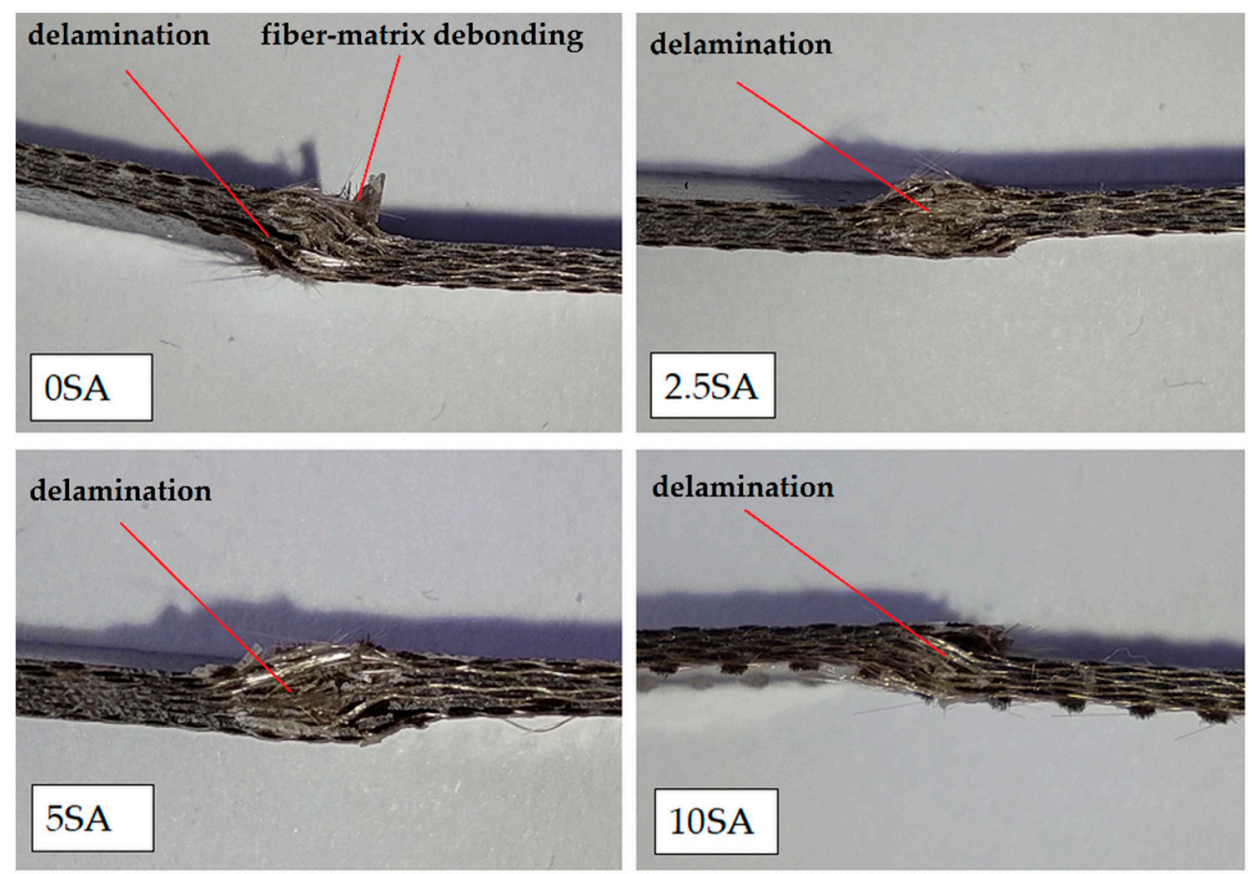

Figure 7. Images of the damaged area of composites modified with sunflower husk ash after the impact test.

The Figure 8 shows the characteristic force-displacement curves recorded during the test. As in the case of composites with $\mathrm{BF}$, it can be observed that after reaching $\mathrm{F}_{\max }$, the force rapidly increases and then begins to increase, which is characteristic of delamination. The introduction of waste filler such as sunflower husk ash into the epoxy matrix made it 
possible to strengthen the structure of the laminate. All the modified composites with SA were characterized by a significantly higher $\mathrm{F}_{\max }$ compared to the unmodified sample.

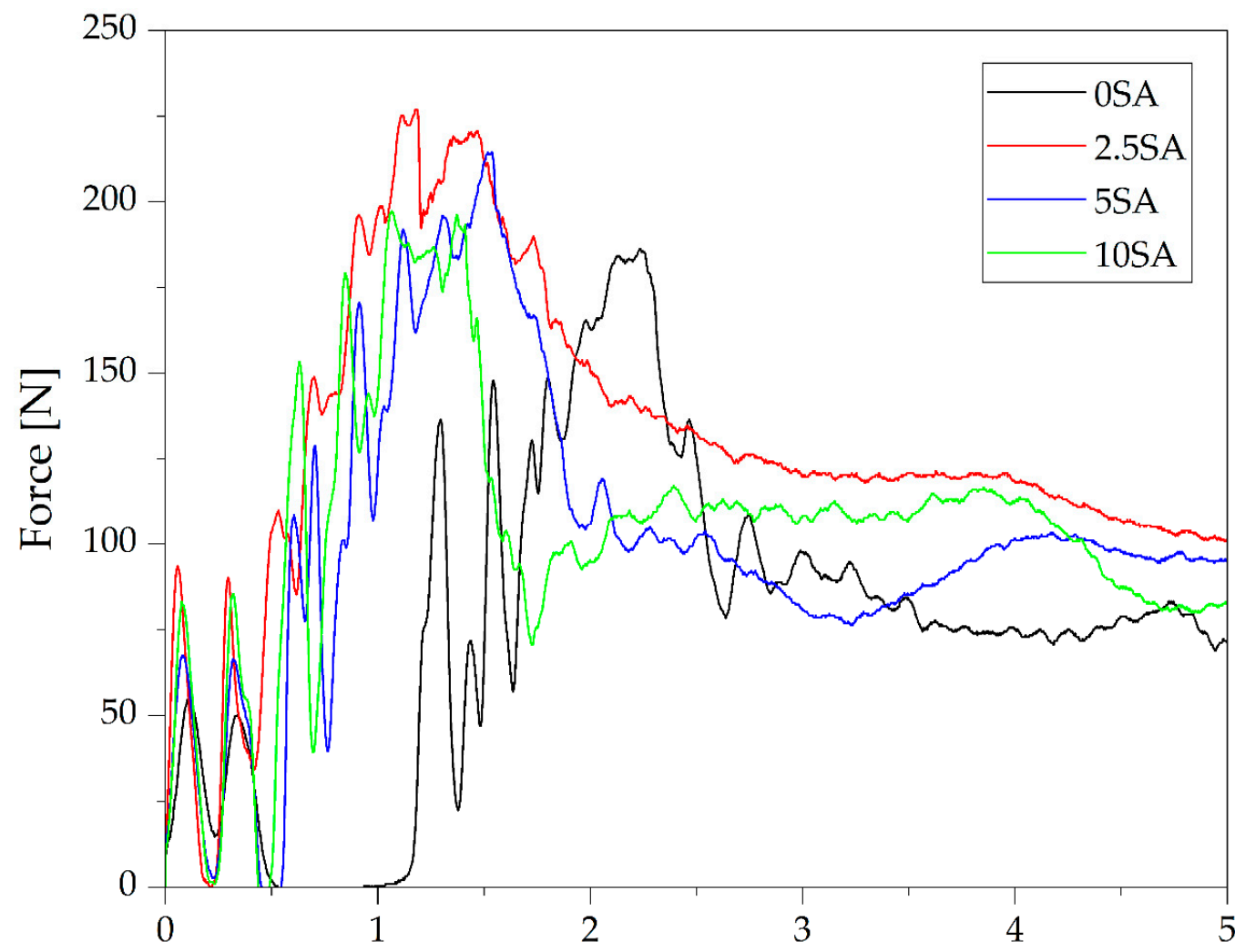

Figure 8. The load-displacement curves of the investigated composites with sunflower husk ash.

A significant difference in the $\mathrm{F}_{\max }$ value between the group of composites from $\mathrm{BP}$ and composites from $\mathrm{BF}$ and $\mathrm{SA}$ results mainly from differences in the type of epoxy resin used and its specific properties.

\subsection{Barcol Hardness}

The hardness determines the resistance of the material to local deformation. To measure this, a hard indenter is placed on the surface of the tested composite and then pressed into the material [37]. If the composite structure is compact and the epoxy resin has adequately covered the reinforcement fibers and has been fully cured, high hardness of the laminates can be achieved. There were no significant differences in the hardness of particular groups of composites. Samples with basalt powder and microfiber had an average hardness of 50, while samples with sunflower husk ash an average hardness of 45. The addition of the filler increased the hardness of the tested materials. The obtained results are summarized in the Table 3. 
Table 3. The Barcol hardness test results.

\begin{tabular}{cc}
\hline Sample & Barcol Hardness \\
\hline epoxy matrix & $45.0 \pm 1.1$ \\
0 BP & $48.4 \pm 1.9$ \\
$2.5 \mathrm{BP}$ & $51.7 \pm 1.1$ \\
$5 \mathrm{BP}$ & $50.3 \pm 1.2$ \\
$10 \mathrm{BP}$ & $52.4 \pm 1.6$ \\
\hline epoxy matrix & $41.5 \pm 1.4$ \\
0 BF & $47.2 \pm 1.2$ \\
$2.5 \mathrm{BF}$ & $49.9 \pm 1.1$ \\
5 BF & $50.4 \pm 1.2$ \\
$10 \mathrm{BF}$ & $53.3 \pm 1.3$ \\
\hline epoxy matrix & $40.1 \pm 1.2$ \\
0 SA & $42.7 \pm 1.2$ \\
$2.5 \mathrm{SA}$ & $44.2 \pm 1.4$ \\
$5 \mathrm{SA}$ & $45.2 \pm 1.1$ \\
$10 \mathrm{SA}$ & $47.1 \pm 1.1$ \\
\hline
\end{tabular}

\section{Conclusions}

The results of the conducted research confirm that the introduction of a powder additive to the epoxy matrix of basalt fiber-reinforced composites is an effective method of improving their impact properties. For composites modified with basalt materials such as basalt powder and basalt microfiber, the greatest improvement in impact strength was obtained with the highest content of these modifiers, i.e., $10 \mathrm{wt} . \%$. In the case of BP composites, an increase in impact strength by $30 \%$ was observed. It can be assumed that the rigid particles of basalt powder are partially chemically combined with the epoxy resin, which strengthens it. For the group of BF-modified materials, the increase in impact strength was not so significant. However, a much greater force was needed to damage all composites containing the basalt microfiber than for the reference sample. Among the tested composites modified with filler, the group of composites with sunflower husk ash showed the most homogeneous properties and the highest impact strength at the level of $60 \mathrm{~kJ} / \mathrm{m}^{2}$. For the modified materials, an increase in impact strength was recorded, respectively: by $44 \%$ for composites with $\mathrm{BP}$, by $7.5 \%$ for composites with $\mathrm{BF}$ and by $2.5 \%$ for composites with SA. The test results confirm that waste fillers such as basalt powder and sunflower husk ash can be successfully used to reinforce sandwich composites. These composites can be used as construction materials with high hardness and impact resistance.

Author Contributions: Conceptualization, D.M.; methodology, D.M. and M.S.M.; formal analysis, M.R.S. and S.S.; investigation, D.M. and M.B.; writing-original draft preparation, D.M.; writing —review and editing, D.M. and M.B. All authors have read and agreed to the published version of the manuscript.

Funding: This research was funded by the Ministry of Science and Higher Education in Poland under Project No 0513/SBAD/4720.

Conflicts of Interest: The authors declare no conflict of interest.

\section{References}

1. Ye, Y.-Y.; Liang, S.-D.; Feng, P.; Zeng, J.-J. Recyclable LRS FRP composites for engineering structures: Current status and future opportunities. Compos. Part B Eng. 2021, 212, 108689. [CrossRef]

2. Andrzejewski, J.; Misra, M.; Mohanty, A.K. Polycarbonate biocomposites reinforced with a hybrid filler system of recycled carbon fiber and biocarbon: Preparation and thermomechanical characterization. J. Appl. Polym. Sci. 2018, 135, 46449. [CrossRef]

3. Barczewski, M.; Mysiukiewicz, O.; Szulc, J.; Kloziński, A. Poly(lactic acid) green composites filled with linseed cake as an agricultural waste filler. Influence of oil content within the filler on the rheological behavior. J. Appl. Polym. Sci. 2019, 136, 47651. [CrossRef] 
4. $\quad$ Aisyah, H.A.; Paridah, M.T.; Sapuan, S.M.; Ilyas, R.A.; Khalina, A.; Nurazzi, N.M.; Lee, S.H.; Lee, C.H. A Comprehensive Review on Advanced Sustainable Woven Natural Fibre Polymer Composites. Polymers 2021, 13, 471. [CrossRef]

5. Shivamurthy, B.; Anandhan, S.; Bhat, K.U.; Thimmappa, B.H.S. Structure-property relationship of glass fabric/MWCNT/epoxy multi-layered laminates. Compos. Commun. 2020, 22, 100460. [CrossRef]

6. Oliwa, R.; Oleksy, M.; Czech-Polak, J.; Płocińska, M.; Krauze, S.; Kowalski, M. Powder-epoxy resin/glass fabric composites with reduced flammability. J. Fire Sci. 2019, 37, 155-175. [CrossRef]

7. Matykiewicz, D. Hybrid Epoxy Composites with Both Powder and Fiber Filler: A Review of Mechanical and Thermomechanical Properties. Materials 2020, 13, 1802. [CrossRef]

8. Khandelwal, S.; Rhee, K.Y. Recent advances in basalt-fiber-reinforced composites: Tailoring the fiber-matrix interface. Compos. Part B Eng. 2020, 192, 108011. [CrossRef]

9. Ricciardi, M.R.; Papa, I.; Impero, F.; Langella, A.; Lopresto, V.; Antonucci, V. Low-temperature effect on the impact and flexural behaviour of basalt composite laminates. Compos. Struct. 2020, 249, 112607. [CrossRef]

10. Mun, S.Y.; Ha, J.; Lee, S.; Ju, Y.; Lim, H.M.; Lee, D. Prediction of enhanced interfacial bonding strength for basalt fiber/epoxy composites by micromechanical and thermomechanical analyses. Compos. Part A Appl. Sci. Manuf. 2021, 142, 106208. [CrossRef]

11. Prasath, K.A.; Amuthakkannan, P.; Arumugaprabu, V.; Manikandan, V. Low velocity impact and compression after impact damage responses on flax/basalt fiber hybrid composites. Mater. Res. Express 2019, 6, 115308. [CrossRef]

12. Fiore, V.; Scalici, T.; Sarasini, F.; Tirilló, J.; Calabrese, L. Salt-fog spray aging of jute-basalt reinforced hybrid structures: Flexural and low velocity impact response. Compos. Part B Eng. 2017, 116, 99-112. [CrossRef]

13. Russo, P.; Simeoli, G.; Cimino, F.; Papa, I.; Ricciardi, M.R.; Lopresto, V. Impact Damage Behavior of Vinyl Ester-, Epoxy-, and Nylon 6-Based Basalt Fiber Composites. J. Mater. Eng. Perform. 2019, 28, 3256-3266. [CrossRef]

14. Dorigato, A.; Pegoretti, A. Fatigue resistance of basalt fibers-reinforced laminates. J. Compos. Mater. 2012, 46, 1773-1785. [CrossRef]

15. Jamali, N.; Khosravi, H.; Rezvani, A.; Tohidlou, E. Mechanical Properties of Multiscale Graphene Oxide/Basalt Fiber/Epoxy Composites. Fibers Polym. 2019, 20, 138-146. [CrossRef]

16. Arshad, M.N.; Mohit, H.; Sanjay, M.R.; Siengchin, S.; Khan, A.; Alotaibi, M.M.; Asiri, A.M.; Rub, M.A. Effect of coir fiber and TiC nanoparticles on basalt fiber reinforced epoxy hybrid composites: Physico-mechanical characteristics. Cellulose 2021, 28, 3451-3471. [CrossRef]

17. Toorchi, D.; Tohidlou, E.; Khosravi, H. Enhanced flexural and tribological properties of basalt fiber-epoxy composite using nano-zirconia/graphene oxide hybrid system. J. Ind. Text. 2020. [CrossRef]

18. Rassokhin, D.; Starokadomsky, D.; Ishchenko, A.; Tkachenko, O.; Reshetnyk, M.; Kokhtych, L. Determining the strength and thermal-, chemical resistance of the epoxy polymer composite filled with basalt micronano fiber in the amount of $15-80 \%$ by weight. East.-Eur. J. Enterp. Technol. 2020, 2, 48-55. [CrossRef]

19. Ricciardi, M.R.; Papa, I.; Coppola, G.; Lopresto, V.; Sansone, L.; Antonucci, V. Effect of Plasma Treatment on the Impact Behavior of Epoxy/Basalt Fiber-Reinforced Composites: A Preliminary Study. Polymers 2021, 13, 1293. [CrossRef]

20. Demirci, İ.; Avc1, A.; Demirci, M.T. Investigation of nano-hybridization effects on low velocity impact behaviors of basalt fiber reinforced composites. J. Compos. Mater. 2021, 55, 401-414. [CrossRef]

21. Matykiewicz, D.; Barczewski, M.; Knapski, D.; Skórczewska, K. Hybrid effects of basalt fibers and basalt powder on thermomechanical properties of epoxy composites. Compos. Part B Eng. 2017, 125, 157-164. [CrossRef]

22. Matykiewicz, D.; Barczewski, M. On the impact of flax fibers as an internal layer on the properties of basalt-epoxy composites modified with silanized basalt powder. Compos. Commun. 2020, 20, 100360. [CrossRef]

23. Stefani, P.M.; Cyras, V.; Tejeira Barchi, A.; Vazquez, A. Mechanical properties and thermal stability of rice husk ash filled epoxy foams. J. Appl. Polym. Sci. 2006, 99, 2957-2965. [CrossRef]

24. Xu, Y.; Li, J.; Shen, R.; Wang, Z.; Hu, P.; Wang, Q. Experimental study on the synergistic flame retardant effect of bio-based magnesium phytate and rice husk ash on epoxy resins. J. Therm. Anal. Calorim. 2021, 146, 153-164. [CrossRef]

25. Tokobaro, P.E.A.; Larocca, N.M.; Backes, E.H.; Pessan, L.A. Effects of mineral fillers addition and preparation method on the morphology and electrical conductivity of epoxy/multiwalled carbon nanotube nanocomposites. Polym. Eng. Sci. 2021, 61, 538-550. [CrossRef]

26. Paleckiene, R.; Sviklas, A.M.; Šlinkšiene, R.; Štreimikis, V. Complex fertilizers produced from the sunflower husk ash. Polish J. Environ. Stud. 2010, 19, 973-979.

27. Drobot, N.F.; Noskova, O.A.; Baranchikov, A.E.; Khoroshilov, A.V.; Fomichev, S.V.; Krenev, V.A. Application of magnetic separation for modifying the composition of basalt raw materials. Theor. Found. Chem. Eng. 2017, 51, 775-780. [CrossRef]

28. Jamshaid, H.; Mishra, R. A green material from rock: Basalt fiber-A review. J. Text. Inst. 2016, 107, 923-937. [CrossRef]

29. Kang, T.J.; Kim, C. Energy-absorption mechanisms in Kevlar multiaxial warp-knit fabric composites under impact loading. Compos. Sci. Technol. 2000, 60, 773-784. [CrossRef]

30. Richardson, M.O.W.; Wisheart, M.J. Review of low-velocity impact properties of composite materials. Compos. Part A Appl. Sci. Manuf. 1996, 27, 1123-1131. [CrossRef]

31. Raajeshkrishna, C.R.; Chandramohan, P.; Babatunde Obadele, A. Friction and thermo mechanical characterization of nano basalt reinforced epoxy composites. Int. J. Polym. Anal. Charact. 2021, 26, 425-439. [CrossRef]

32. Kazemi, M.E.; Shanmugam, L.; Li, Z.; Ma, R.; Yang, L.; Yang, J. Low-velocity impact behaviors of a fully thermoplastic composite laminate fabricated with an innovative acrylic resin. Compos. Struct. 2020, 250, 112604. [CrossRef] 
33. Khosravi, H.; Eslami-Farsani, R. On the mechanical characterizations of unidirectional basalt fiber/epoxy laminated composites with 3-glycidoxypropyltrimethoxysilane functionalized multi-walled carbon nanotubes-enhanced matrix. J. Reinf. Plast. Compos. 2016, 35, 421-434. [CrossRef]

34. Daramola, O.O.; Adediran, A.A.; Adegun, M.H.; Sadiku, E.R.; Olayanju, T.M.A. Olayanju effect of guinea corn husk ash on the mechanical properties and wear behaviour of epoxy matrix composites. Int. J. Civ. Eng. Technol. 2018, 9, 1207-1216. Available online: http:/ / www.iaeme.com/ijciet/issues.asp (accessed on 30 June 2021).

35. Vivek, S.; Kanthavel, K. Effect of bagasse ash filled epoxy composites reinforced with hybrid plant fibres for mechanical and thermal properties. Compos. Part B Eng. 2019, 160, 170-176. [CrossRef]

36. Naidu, A.L.; Kona, S. Experimental Study of The Mechanical Properties of Banana Fiber and Groundnut Shell Ash Reinforced Epoxy Hybrid Composite. Int. J. Eng. 2018, 31, 659-665.

37. Webo, W.; Masu, L.; Maringa, M. The Impact Toughness and Hardness of Treated and Untreated Sisal Fibre-Epoxy Resin Composites. Adv. Mater. Sci. Eng. 2018, 2018, 8234106. [CrossRef] 